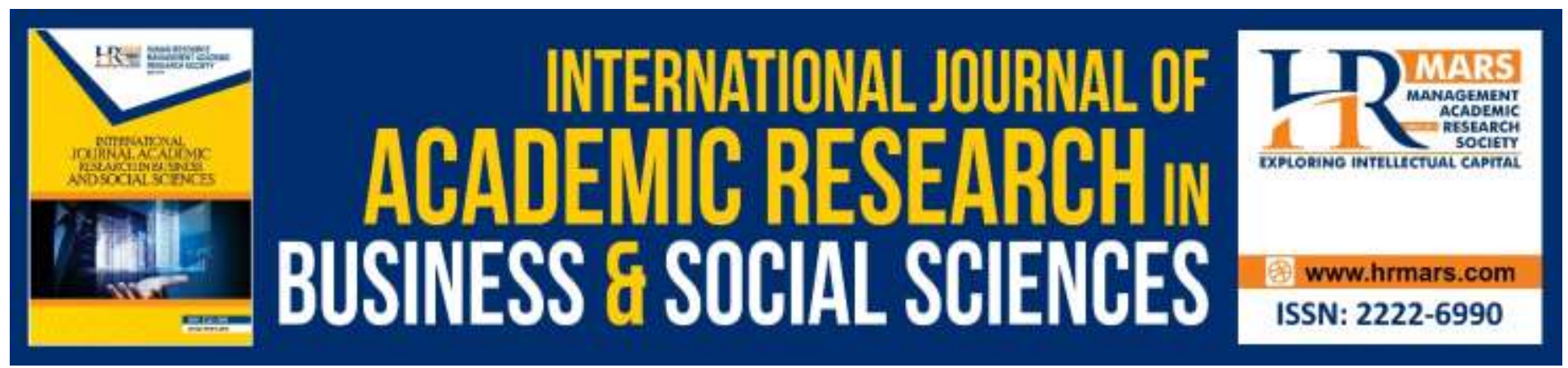

\title{
Influence of Psychosocial Factors on Health Behaviours Among Undergraduates in Malaysia
}

\section{Roxana Dev Omar Dev, Tengku Fadilah Tengku Kamalden, Soh Kim Geok, Maria Chong Abdullah, Ahmad Fauzi Mohamad Ayub \& Ismi Arif Ismail}

To Link this Article: http://dx.doi.org/10.6007/IJARBSS/v9-i11/6707

DOI: 10.6007/IJARBSS/v9-i11/6707

Received: 09 October 2019, Revised: 29 October 2019, Accepted: 12 November 2019

Published Online: 29 November 2019

In-Text Citation: (Dev et al, 2019)

To Cite this Article: Dev, R. D. O., Kamalden, T. F. T., Geok, S. K., Abdullah, M. C., Ayub, A. F. M., \& Ismail, I. A. (2019). Influence of Psychosocial Factors on Health Behaviours Among Undergraduates in Malaysia . International Journal of Academic Research in Business and Social Sciences, 9(11), 1382-1401.

Copyright: (C) 2019 The Author(s)

Published by Human Resource Management Academic Research Society (www.hrmars.com)

This article is published under the Creative Commons Attribution (CC BY 4.0) license. Anyone may reproduce, distribute, translate and create derivative works of this article (for both commercial and non-commercial purposes), subject to full attribution to the original publication and authors. The full terms of this license may be seen at: http://creativecommons.org/licences/by/4.0/legalcode

Vol. 9, No. 11, 2019, Pg. $1382-1401$

Full Terms \& Conditions of access and use can be found at http://hrmars.com/index.php/pages/detail/publication-ethics 


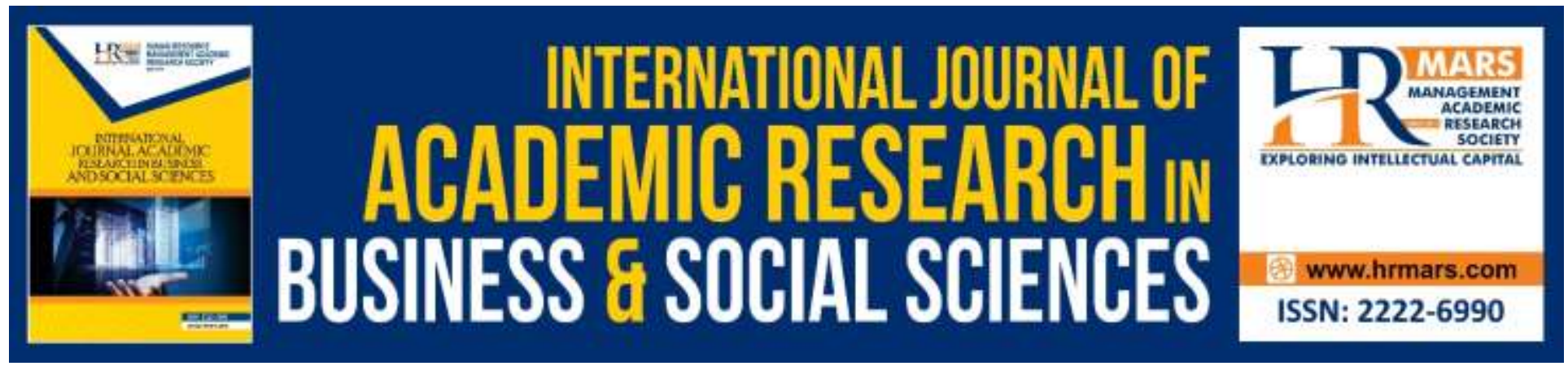

\title{
Influence of Psychosocial Factors on Health Behaviours Among Undergraduates in Malaysia
}

\author{
Roxana Dev Omar Dev, Tengku Fadilah Tengku Kamalden, Soh \\ Kim Geok, Maria Chong Abdullah, Ahmad Fauzi Mohamad Ayub \\ \& Ismi Arif Ismail
}

Faculty of Educational Studies, Universiti Putra Malaysia, 43400 Serdang, Selangor, Malaysia.

\begin{abstract}
Changes in technology-oriented lifestyles and the advancement of information technology have affected university students' values, culture, thinking, lifestyle and character. Unhealthy health behaviors such as smoking and free sex have increased among university students in Malaysia (Roxana et al., 2018). If no intervention is implemented in the education system, this problematic character will become a reference that disrupts the society. Therefore, active steps should be taken to address this problem. The main aim of this study is to develop a model of health behaviour by identifying the relationship of a psycho-social variant of spiritual intelligence to various mediators, which are emotional intelligence and self-efficacy towards health behaviour among undergraduate students in Malaysia. The model is based on the Theory of Triadic Influence (Fly \& Petraitis (1994)). The study uses four instruments namely the Health Behavior Questionnaire (adapted from Bobroff, 2015), the General Self-Efficacy Scale (Schwarzer \& Jerusalem, 1993), Spiritual Inteligence Self-Report Inventory (King, 2008), and Assesssment of Emotional Scale (Schutte, Malouff \& Bhullar, 2009). A randomized proportionate stratified sampling technique was used with a sample of 400 students living in the college at Universiti Putra Malaysia. The structural model of the study with 6 paths was tested and only five paths showed significant effects. This study has shed new light on measuring self-efficacy through students' perceptions. Few researchers have identified self-efficacy as an important factor in making predictions about health behaviors (Mathumardhi \& Suparna, 2016; Jamshidi et al., 2018) however, high self-efficacy will be meaningless if there is no authentic way in addressing intrinsic aspects of life in terms of spirituality (Mathumardhi \& Suparna, 2016; Gwahula, 2018). Spiritual intelligence and high self-efficacy can produce quality students and care about health behaviors. Keywords: Health Behaviour, Psychosocial Factors, Undergraduates
\end{abstract}




\section{Introduction}

University students are the future leaders of future generations. Succeed with flying colours at the university is the dream of every student which can be the defining factor for a successful life. In order to succeed, students need to be dedicated, disciplined, and motivated (Salami, 2010). In addition to being busy attending lectures and completing assignments, university students must be actively involved in their residential college activities as well to activate their dormitory eligibility. This can lead to excessive pressure or distressed (Ekpenyong, Daniel \& Aribo, 2013; Kimball \& Freysinger, 2003). Difficulties in coping with the pressures with healthy stress management strategies such as relaxation and recreation can lead to negative health behaviours, failure in academic performance and negative attitudes towards learning (So \& Park, 2016; Salami, 2010). Behavioural health problems among university students should be of concern as they may affect self-image and self-esteem (Piqueras et al., 2011) and may indirectly affect future character. Negative health behaviours among university students may be a lifelong problem; namely, at work, married life and old age (Quartiroli \& Maeda, 2016; Huntsinger \& Luecke, 2004). Even more worrying is the attitude of students who frequently use mobile phones to fill their leisure time would potentially increase negative health behaviours as well as mental problems (Peraman \& Pasuraman, 2016). In conclusion, these negative health behaviours will affect the country's productivity, economy and prosperity. As such, positive health behaviour interventions should be the agenda of every institution of higher learning for the development of first-class character to be held by every graduate.

According to WHO (2014), balanced health comprises physical, spiritual, intellectual, emotional, and social health which is in line with the National Philosophy of Education. Therefore, it is more important to consider all the factors involved in the study of health behaviors. However, due to the limitations of the research, researchers have selected the most important factors that influence health behaviors among undergraduate students in Malaysia. Therefore, this study focused on emotional intelligence (EI), spiritual intelligence (SI), and self-efficacy (SE) on health behavior (HB). El and SI were chosen because these two factors have been identified by many researchers as catalysts or determinants of factors for well-being and successful living (Aminuddin, 2009). Aminuddin (2009) and many other studies (Sodhi, 2016; Madhumarthi \& Suparna, 2017) have shown that high El and SI will encourage a student to take responsibility for their health and to adopt positive health behaviors. Finally, self-efficacy was also chosen as the determining factor as it was considered an important factor in the development of university student behavior (Tehrani \& Nikpour, 2014; Saksvig et al., 2005). From the study of Glanz, Rimer, and Lewis (2002), high self-efficacy can be a pillar of a sustainable healthy lifestyle. Therefore, self-efficacy was taken to be used as mediator variable in this study.

Therefore, the objective of this study was to develop a model of health behavior by identifying the relationship of one psycho-social variable namely spiritual intelligence to mediators, emotional intelligence and self-efficacy in health behavior among pre-graduate students in Malaysia.

Health behaviors are actions taken by individuals that may influence health (Short \& Molbourn, 2015). These actions may be intentional or unintentional and may promote or 
diminish one's health. Actions that can be classified as health behaviors are smoking, substance use (illicit), eating habits, physical activity, sleeping routine, sexual activity, seeking health care behaviors, adherence to prescribed medical care and stress management (Short \& Molbourn, 2015).

The concept of positive health behaviors is based on behaviors that can prevent illness and protect and improve one's health (Sarafino, 2002), while negative or risky health behaviors are behaviors that may affect or endanger one's health (Sarafino, 2002). Examples of positive health behaviors include healthy eating habits, regular physical activity or exercise, abstaining from alcohol and smoking habits, and regular medical checkups. Whereas, negative health behaviors can be seen in examples such as not eating a well-balanced diet, inactive lifestyle, smoking and drinking alcohol, and avoiding health checks.

The full conceptual framework of this study is based on Triad Influence Theory (TTI; Flay and Petraitis, 1994). TTI combines various theories into a framework in which exogenous variables or independent variables are grouped into three streams of influence and three stages of causation (Bavarian, Flay, Ketcham, Smit, Kodama, Martin \& Saltz, 2014). The three streams of influence are divided into personality traits that influence self-efficacy (ie, intrapersonal flow), social bonds that influence behavioral norms (i.e., social context) and cultural environment that influence attitudes to behavior (which is socio-cultural). These three stages are from the main causes (which an individual has least control over such as politics, education level and socioeconomic status), distal causes, and proximal causes. For sustainable change in health behaviors, changes in the main cause have the biggest and longest lasting effects, but they are difficult to change due to static factors. Therefore, researchers are more interested in looking at factors or variables that can be easily changed or adapted in terms of health behaviors during university students' years in campus. Because distal and distal-proximal influences may be more likely to reflect students' interactions between social situations, cultural environments and intrapersonal skills, the use of distal and proximal or distal-proximal influences may have a better chance for a student to attain positive health behaviors. Therefore, in line with WHO's (2014) definition of health and past research literature; spiritual intelligence, emotional intelligence and self-efficacy were selected. as variables in shaping the health behavior model for university students.

In this study, SI was chosen to meet cultural and environmental stream, and El was selected to meet intrapersonal stream. According to the definition of spiritual intelligence, $\mathrm{SI}$ is the ability to work on aspects of self-concealment of the Divine or Almighty that influence the meaning, value and purpose of life (King \& Cicco, 2008). While emotional intelligence (EI) reflects the skills, or the ability to identify, evaluate, and manage one's emotions (Serrat, 2017). Selfefficacy (SE) is a person's expectation or belief in any behavior that needs to be described in order to achieve a goal (Schwarzer \& Warner, 2013). SE was chosen because it is part of the proximal level predictor of TTI; which is a direct influence on health behavior and is under the control of the individual, though still influenced by distal and primary (final) factors as previously mentioned. Previous studies have shown that proximal variables included in TTI such as selfefficacy are predictors of health behavior (Flay et al., 2009). In this study, SE is defined as the 
mediator and also referred to by other studies (Darker, French, Eves \& Sniehotta, 2010, Hyde, Hankins, Deale, \& Marteau, 2008). El is also defined as the mediator as shown in the study by Jacobs, Wollny, Sim, and Horsch (2016). Here, El is chosen as the distal-proximal variable; different from the original TTI framework called EI as a distal variable. This, then, is the contribution of the theory shift or paradigm to the existing theory of health behavior. As a note, this study named SI as an exogenous variable, while EI, SE and HB as endogenous variables; where the exogenous variables are independent variables while the endogenous variables are independent and intermediate variables. The conceptual framework for the study is shown in Figure 1.

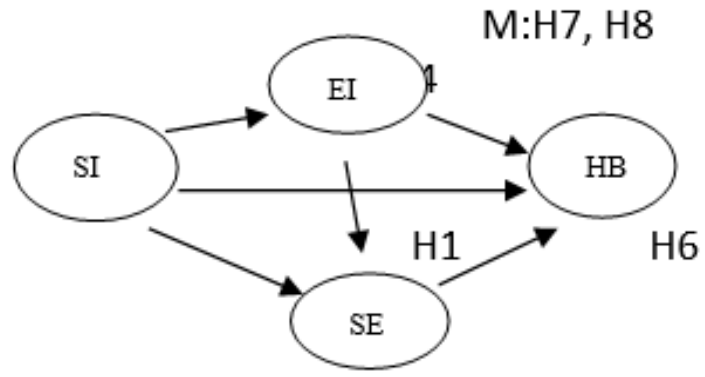

$\mathrm{H} 2$

$\mathrm{M}: \mathrm{H9}, \mathrm{H} 10$

Figure 1 Conceptual framework (with hypothesis) of health behaviour where SI, spiritual intelligence; $\mathrm{El}$, emotional intelligence; $\mathrm{SE}$, self-efficacy, $\mathrm{HB}$, health behaviour dan $\mathrm{M}$, mediator.

SI and health behaviors

According to a study conducted by Anye, Gallien, Bian, Ches and Moulton (2013), spiritual intelligence plays an important role in reducing risky health behaviors and improving quality of life. The study aimed to examine the relationship between spiritual intelligence and various aspects of health-related quality of life. In the study, 225 college students were surveyed using the Spiritual Well-Being Scale and Health Related Quality of Life instrument. Results showed that students with higher spiritual intelligence has better quality of life and health behavior. Various other studies have supported such findings (Bretching et al., 2012; Kulis et al., 2012; Burris et al., 2009). Based on this finding, the first hypothesis is; H1: Spiritual intelligence has a positive relationship with health behavior among undergraduate students at Universiti Putra Malaysia (UPM).

\section{El and Health Behaviors}

It can be concluded that many studies support a positive relationship between $\mathrm{El}$ and health behaviors (Lana, Baizan, Faya-Ornia \& Lopez, 2015; Fernandez-Abascal \& Martin-Diaz, 2015). It also shows that high emotional intelligence reduces risky health behaviors where $\mathrm{EI}$ is negatively associated with risky health behaviors (Rivers et al., 2013). This will facilitate the implementation of support services for university students in avoiding risky health behaviors. 
Most studies conducted so far have described bilateral relationships. Further exploration and causal effects need to be made to distinguish the direction of the study. Thus, after studying the Triad Influence Theory (TTI) that integrates the previously mentioned theories, it highlights researchers' opinion that health behaviors are more complex than expected. Through personal experience the researcher believe El is also a mediator and not just a predictor variable. However, for direct relationships, the second hypothesis is; $\mathrm{H} 2$ : Emotional intelligence has a positive relationship with health behaviors among undergraduate students at UPM.

\section{SE and Health Behaviors}

Self-efficacy is one of the factors that can influence health behaviors. In terms of positive health behaviors, high self-efficacy promotes positive health behaviors (Perker \& Bermeck, 2011). In terms of negative behaviors, high self-efficacy reduces risky health behaviors that are either at university or in school (Mee, 2014; Valois, Zullig, Kammermann \& Kershner, 2013; Veselska, Geckova, Reijneveld, \& Van-Dijk, 2011). This shows that self-efficacy is important in promoting health. Thus, the third hypothesis is; H3: Self-efficacy has a positive relationship with health behaviour among undergraduate students in UPM.

\section{SI and EI}

Following a variety of behavioral theories, SI has been identified as a core capability or intelligence that guides other capabilities (Fry, 2003; Romel \& Gan, 2008). In particular, several researchers have shown that SI influences EI (Zohar \& Marshall, 2000; Hoseini et al., 2010). Thus, the fourth hypothesis is; $\mathrm{H} 4$ : SI has a positive relationship to emotional intelligence (EI) among undergraduate students at UPM.

\section{SI and SE}

Spiritual intelligence is one of the factors that can enhance self-efficacy. Recent studies conducted by other researchers also showed that spiritual intelligence has a significant and positive relationship with one's self-efficacy. Thus, the fifth hypothesis is; H5: SI has a positive relationship with self-efficacy (SE) among undergraduate students at UPM.

\section{El and SE}

High emotional intelligence is associated with the ability to successfully cope with stress. Claros and Sharma (2012) identified university students with higher self-efficacy scores associated with lower scores on the Alcohol Use Disorders Identification Test (AUDIT). Human health behaviors are complex but quantitative studies are usually aimed at understanding the variables studied to facilitate understanding. Previous researchers have concluded that university students with higher levels of emotional intelligence have shown less to be influenced by peer norms in alcohol consumption (Ghee \& Johnson, 2008). This indicates that students with high EI also have high SE. Thus, the sixth hypothesis is; H6: El has a positive relationship with self-efficacy (SE) among undergraduate students at UPM. 


\section{The Role of El as a Mediator}

There is a lack of studies linking El as a mediator between SI and SE as well as health behaviors (HB). However, a study from Hanafi (2010) states that there is a stronger relationship between spiritual intelligence and academic performance indirectly than directly if $\mathrm{EI}$ is a mediator. This implies that there is a role of El as a mediator between $\mathrm{SI}$ and academic performance. This empirical result was taken as a guide to the relationship between $\mathrm{SI}$ and SE aS well as $\mathrm{SI}$ and $\mathrm{HB}$, with $\mathrm{El}$ as a mediator. Thus, the seventh and eighth hypotheses are; $\mathrm{H7}$ : $\mathrm{El}$ is the mediator of the relationship between SI and HB undergraduate students at UPM and H8: EI is the mediator of the relationship between SI and SE in among undergraduate students at UPM.

\section{The Role of SE as a Mediator}

Few studies have found that students with high spiritual intelligence will have greater confidence in believing in God and tendency to have higher capability in self-efficacy (Jamshidi, Moghadam, Ghorbani and Farhoush, 2018; Noori, 2016). Studies have showed that high SE can reduce anxiety and thus improve academic performance. Although there are limited studies linking SE, SI and HB, there are some studies that have found high correlation between spiritual intelligence and self-efficacy in psychological well-being, mental health and health (Adeyemo \& Adeleye, 2008); De Souza, Torres, Barbossa, De Lima \& De Souza, 2014). This shows relevant results in which self-efficacy according to De Souza et al. (2014) promote positive health behaviors. Thus, on the basis of this, the ninth and tenth hypotheses are; H9: SE is the mediator of the relationship between SI and HB among undergraduate students at UPM and H10: SE is the mediator of the relationship between EI and HB among undergraduate students at UPM.

\section{Materials and Methods Study Sample}

This study is a correlation study. The respondents selected in this study were those living in residential colleges at a public university in Malaysia, Universiti Putra Malaysia (UPM). Sampling from this group will represent undergraduate students at the university as $95 \%$ of undergraduate students reside at UPM residential colleges. Thus, about 400 undergraduate students were recruited from 16 residential colleges using proportionate stratified sampling techniques. The sample size of the study complies with the Cohen and Cochran sample size determination techniques. Demographic characteristics of respondents are shown in Table 1.

\section{Research Questionnaire}

There are four instruments used for this research questionnaire. All instruments for this study was translated back to back, meaning that the original version of the instruments which was all in English were translated to Malay, and were translated back in English with the context of Malaysian population. Thus, each item of all the instruments are made in two languages, namely English and Bahasa Melayu. Written permission for each instrument has also been obtained from all instrument authors. The Assessing Emotions Scale (TAES), developed by Schutte, Malouff and Bhullar (2009) was used to measure four aspects of emotional intelligence 
(Salovey \& Mayer, 1990); 1) emotional perception, 2) managing one's own emotions, 3) managing other people's emotions, and 4) using emotions. The TAES consists of 33 items using a 5- Likert scale based on four dimensions. The scale ranged from $1=$ strongly disagree, $2=$ disagree, $3=$ somewhat agree, 4 = agree, and 5 = strongly agree. Cronbach's alpha reported by Schutte et al. (2009) is at 0.90 while for this study it is 0.87 . The Generalized Self-Efficacy Scale (GSES) was developed by Schwarzer and Jerusalem (1995). The GSES is a 10-item instrument that measures self-efficacy. It is measured on a 4 Likert scale ranging from $1=$ Not at all to $4=$ Very accurate. Cronbach's alpha coefficient of GSES ranged from 0.75 to 0.80 , whereas for this study it was 0.90 .

The Spiritual Intelligence Self-Report Inventory (SISRI-24) is an instrument used to measure the spiritual intelligence of adolescents formed by King (2008) and King and DeCicco (2010). There are 24 items in total for the SISRI-24 instrument with four sub constructs. There were five Likert scales with $0=$ absolutely not true about me, $1=$ not true about me, 2 = slightly true about me, 3 = true about me and 4 = very true about me. In this study, scale 1 was changed to score 1 , scale 2 was changed to score 2 and so on. The range of possible scores ranges from 0 to 96, where higher scores represent higher SI levels. Item 6 is a negative statement in which reverse encoding is required. Cronbach's alpha for SISRI-24 was high at 0.91 . Finally, the Heath Behavior Questionnaire (HBQ) adapted from the Health Lifestyle Test, was developed by Bobroff (2007) for the Department of Health and Human Services, Public Services, USA. There were 32 items with six constructs: 1) smoking, 2) eating habits, 3) physical activity, 4) alcohol and drugs, 5) stress management and 6) safety, which were rated on a 5-point Likert scale of $0=$ almost never , 1 = rarely, 2 = sometimes, 3 = often, and 4 = always. This study obtained a Cronbach alpha of 0.87 and from a previous study Cronbach's alpha ranged from 0.8 to 0.95 . 
INTERNATIONAL JOURNAL OF ACADEMIC RESEARCH IN BUSINESS AND SOCIAL SCIENCES

Vol. 9, No. 11, November, 2019, E-ISSN: 2222-6990 @ 2019 HRMARS

Table 1 Demographic data of university students $(n=400)$

\begin{tabular}{|c|c|c|}
\hline Items & $\mathbf{n}$ & $\%$ \\
\hline \multicolumn{3}{|l|}{ Gender } \\
\hline Male & 200 & 50 \\
\hline Female & 200 & 50 \\
\hline \multicolumn{3}{|l|}{ Race } \\
\hline Melayu & 339 & 84.9 \\
\hline Cina & 29 & 7.3 \\
\hline India & 13 & 3.3 \\
\hline Bumiputera & 19 & 4.8 \\
\hline \multicolumn{3}{|l|}{ College } \\
\hline 17 & 50 & 12.5 \\
\hline 12 & 36 & 9.0 \\
\hline 14 & 36 & 9.0 \\
\hline 15 & 35 & 8.8 \\
\hline 16 & 34 & 8.5 \\
\hline 13 & 22 & 5.5 \\
\hline 11 & 19 & 4.8 \\
\hline KPZ & 19 & 4.5 \\
\hline 10 & 18 & 4.5 \\
\hline 6 & 18 & 4.5 \\
\hline $\mathrm{KC}$ & 18 & 4.5 \\
\hline KOSASS & 18 & 4.5 \\
\hline 5 & 17 & 4.3 \\
\hline 2 & 17 & 4.3 \\
\hline KTDI & 17 & 4.3 \\
\hline KTP & 17 & 4.3 \\
\hline KMR & 9 & 2.3 \\
\hline
\end{tabular}

\section{Data Preparation and Analysis}

The reliability and validity of the constructs were performed as a data preparation process and are shown in Table 2. Internal consistency tests were conducted on four constructs using Cronbach's alpha and found that values ranged from 0.88 to 0.90 . Data validation tests were performed using validation factor analysis (CFA). From the CFA test, it was found that all constructs were fit from the fit indices except HB; but from the measurement model, the HB index is fit. CFA and hypothesis testing were performed using structural equation modeling (SEM) software using IBM SPSS AMOS software version 21. Convergent validity and discrimination were tested using guidelines set by Hair et al. (2009) which comprised of (1) composite reliability (CR), where all constructs exceed $0.7,(2)$ average extracted variance (AVE), where AVE for all 
INTERNATIONAL JOURNAL OF ACADEMIC RESEARCH IN BUSINESS AND SOCIAL SCIENCES Vol. 9, No. 11, November, 2019, E-ISSN: 2222-6990 @ 2019 HRMARS

constructs exceeds 0.5 and (3) AVE for each construct exceeds R2 from other constructs. In addition, mediator analysis of El and SE were conducted according to the procedure proposed by Baron and Kenny (1986) and Mathieu and Taylor (2006). Whereas, descriptive statistics (mean and standard deviation) of constructs and correlations between constructs were analyzed using IBM SPSS version 22 and their values are presented in Table 3.

Table 2 Reliability and validity data of Construct Factor Analysis (CFA)

\begin{tabular}{llll}
\hline Construct & $\begin{array}{l}\text { No. } \\
\text { Item/Dimension }\end{array}$ & $\begin{array}{l}\text { Cronbach } \\
\text { Alpha }\end{array}$ & CFA (fit) \\
\hline EI & $33 / 4$ & .884 & $\begin{array}{l}\mathrm{X}^{2}=1.39, \mathrm{p}=0.25, \mathrm{RMSEA}=0.032, \mathrm{GFI}=0.99, \\
\mathrm{NFI}=0.99, \mathrm{CFI}=0.99\end{array}$ \\
\hline $\mathrm{SI}$ & $24 / 4$ & .909 & $\begin{array}{l}\mathrm{X} 2=4.78, \mathrm{p}=0.00, \mathrm{RMSEA}=0.08, \mathrm{GFI}=0.99, \\
\mathrm{NFI}=0.99, \mathrm{CFI}=0.99\end{array}$ \\
\hline $\mathrm{SE}$ & $10 / 1$ &. & $\begin{array}{l}\mathrm{X} 2=4.00, \mathrm{p}=0.00, \mathrm{RMSEA}=0.08, \mathrm{GFI}=0.96, \\
\mathrm{NFI}=0.96, \mathrm{CFI}=0.97\end{array}$ \\
\hline $\mathrm{HB}$ & $32 / 4$ & .885 & $\mathrm{X} 2=19.08, \mathrm{p}=0.00, \mathrm{RMSEA}=0.08, \mathrm{GFI}=0.95$, \\
& & .919 & $\mathrm{NFI}=0.92, \mathrm{CFI}=0.92$
\end{tabular}

El: Emotional Intelligence; SI: Spiritual Intelligence; SE: Self-Efficacy; HB: Health Behaviour; X2, chi square; RMSEA, root mean error approx (<0.08), GFI, goodness of fit index (>0.9); NFI, normal fit index (>0.9); CFI, comparative fit index (>0.9)

Table 3 Mean, standard deviation, correlation between construct, AVE dan CR

\begin{tabular}{lllllllll}
\hline Konstruk & Min & S.P & EI & SI & SE & HB & CR & AVE \\
\hline EI & 3.67 & 0.41 & 1 & 0.396 & 0.161 & 0.158 & .880 & .647 \\
SI & 2.72 & 0.34 & $0.564 * *$ & 1 & 0.182 & 0.204 & .922 & .747 \\
SE & 3.10 & 0.49 & $0.398^{* *}$ & $.442 * *$ & 1 & 0.197 & .885 & .509 \\
HB & 2.87 & 0.46 & $0.354 * *$ & $.363 * *$ & $.395 * *$ & 1 & .800 & .502 \\
\hline
\end{tabular}

EI: Emotional Intelligence; SI: Spiritual Intelligence; SE: Self-Efficacy; HB: Health Behaviour; AVE: Average Variance Extracted; CR: Composite Reliability; *Value above diagonal (1) is R²; Significant at 0.001

\section{Results and Discussion}

The significant relationship or influence between the constructs is shown in Figure 2. The results of assessing the proposed model fit indicated that Chi-square $=761.371(\mathrm{df}=340)$, Relative Chi-Sq $=2.239(p=.000) \mathrm{GFI}=0.880, \mathrm{AGFI}=0.857, \mathrm{CFI}=0.936, \mathrm{IFI}=0.937, \mathrm{NFI}=0.891, \mathrm{TLI}=$ 0.929 , RMSEA $=0.056$. Based on the model fit criteria, all the indices are acceptable. However, after testing the proposed structural model, one path was seen insignificant which was from path $\mathrm{EI} \rightarrow \mathrm{HB}$ (H04). Hence, the non-significant path was removed from the structural model and a revised structural model was created (Refer to Figure 2). The indices of the revised structural model are: Chi-square $=848.955(\mathrm{df}=395)$, Relative Chi-Sq $=2.149(\mathrm{p}=.000) \mathrm{GFI}=0.875, \mathrm{AGFI}=$ 
0.853, $\mathrm{CFI}=0.934, \mathrm{IFI}=0.935, \mathrm{NFI}=0.885, \mathrm{TLI}=0.923, \mathrm{RMSEA}=0.054$. Based on the revised structural model the relative $\chi 2$ value has a lower value of 0.090 and also a lower value of AIC of 1.469. Hence, it is concluded that the revised model (Figure 2) has a better fit as compared with the proposed structural model. According to the first and third hypotheses it can be concluded that SI and SE have a significant relationship with health behavior (HB). SI had a significant relationship or direct effect on $\mathrm{HB}$ with $\beta=.248$; $C . R=3.354, p<.05$. This finding supports the findings of Ahghar (2014) study that shows that university students with high spirituality can reduce their use and addiction to alcohol and drugs. Studies from Alaei, Zabihi, Ahmadi, Doosti and Saberi (2017) also showed that working people have better control over alcohol abuse when their spiritual intelligence is higher. Galanter, Dermatis and Santucci (2014) also conclude that the spiritual awakening from active spiritual practices can reduce the desire to consume alcohol. In short, spiritual intelligence can facilitate problem solving and achieve goals in promoting health. In this case, it can be used to help with difficult situations such as substance abuse. Establishing a moral order through faith and religion can explain the relationship between spiritual intelligence and hazardous substance used (Wills, Year \& Sandy, 2003). It can therefore be assumed that college students in UPM who tend to spend time in religious activities will be less involved in alcohol and drug abuse. It may also be the abstain use of alcohol in college may also reduce or attempt to use any illegal substance. In addition, the presence of mosques and churches on campus also facilitates religious activities for students and this promotes positive attitudes and character as well. This is in line with the TTI framework for predicting health promotion through the environment and culture where in this case spiritual intelligence is referred to as the distal predictor of health behavior.

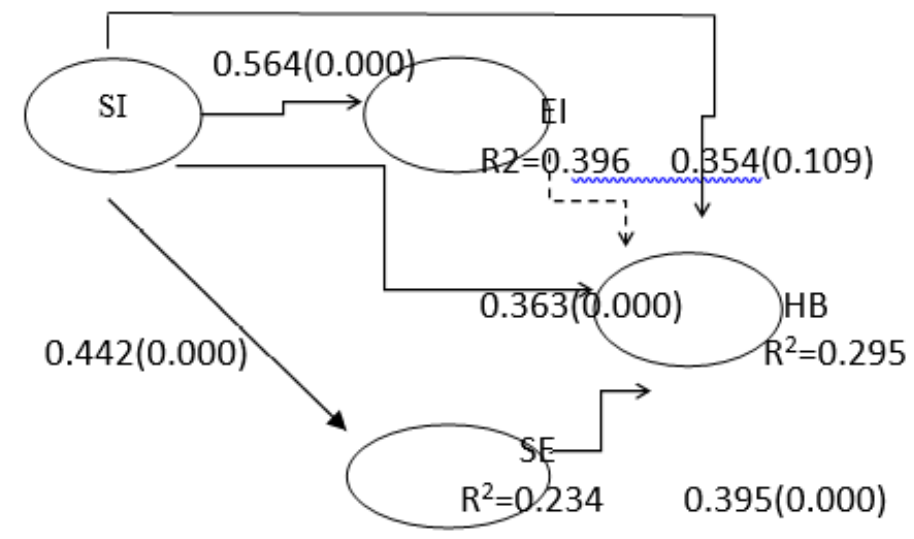

Non-significant Path

Significant Path

Figure 2. Factors affecting health behaviours of undergraduates. All relationships are significant except for EI-HB; numbers given in the parentheses are p-values. El: Emotional Intelligence; SI: Spiritual Intelligence; SE: Self-Efficacy; HB: Health Behaviour. Model fit indices: 
Relative Chi-Sq $=2.149(p=.000) \mathrm{GFI}=.875, \mathrm{AGFI}=0.853, \mathrm{CFI}=0.934, \mathrm{IFI}=0.935, \mathrm{NFI}=0.885$, $\mathrm{TLI}=0.923, \mathrm{RMSEA}=0.054$.

Self-efficacy (SE) was seen to significantly associate health behaviour with $\beta=.297 ; C . R=$ $4.425, p<.05$. This is coherent with the study by Charkazi et al. (2016) which showed SE could enhance oral health behaviour among school children and adolescents. According to Charkazi and colleagues (2016) students with high self-efficacy effectively cope better with perceived barriers compared to those with lower self-efficacy. A study by Pauline (2013) significantly showed that self-efficacy increases physical activity engagement among college students. About $86 \%$ of the studies exploring health promotion model reported self- efficacy as a leading factor of health promotion (Kamran, Azadbakht, Sharifirad, Mahaki, \& Mohebi, 2015). In the vast majority of studies conducted on health promotion behaviours, self- efficacy is the strongest predictors of intention and health behavior (Kamran et al., 2015; Breaux-Shropshire, Brown, Pryor, \& Maples, 2012). From the researcher point of view, as individuals increase in their self-efficacy, they become more intrinsically motivated to be healthy and fit, which leads to an increase in health promotive behavior.

However, as in for the third hypothesis, no significant relationship was seen in terms of $\mathrm{El}$ and $\mathrm{HB}(\beta=.118 ; \mathrm{C} . \mathrm{R}=1.604, p>.05)$ which negates most researches in the past. Most studies revealed significant positive relationship between $\mathrm{EI}$ and promotive health behaviour especially in physical activity engagement among university students (Li et al., 2009) and adults (Roxana et al., 2014). Furthermore, most studies also showed El could reduce health risk behaviour such as smoking and alcohol abuse among college students (Azzam \& Elghonemy, 2008; Claros \& Sharma, 2012; Hill \& Maggi, 2011). However, this study does not support previous findings. This could probably be due to misappropriation of health dimensions and behaviours that were selected from various dimensions of self-report El (Fernández-Abascal \& Martín-Díaz, 2015). For example, Li et al (2009) and Roxana et al. (2018) used global total score of emotional intelligence with different physical activity levels (low, moderate and high) to determine the relationships. Physical activities were calculated using International Physical Activity Questionnaire (IPAQ) which is a well-known measurement calculated in METS on daily physical activity for a week. This was compared to Schuette's Assessing Emotions Scale which is a self-report El instrument as a whole, regardless of individual differences. Studies have identified that different instruments used to measure El could also result differentiation (Fernández-Abascal and Martín-Díaz , 2015; Mikolajczak et al., 2015; Fernández-Berrocal \& Cabello, 2016).

Based on the findings in related to El (fourth hypothesis), it can be concluded that $\mathrm{SI}$ has a significant relationship on El since the hypothesis was supported $(\beta=.629, C . R=11.387, p<.001)$. Before 1995, it was thought that Intellectual Quotient (IQ) is the main intelligence that facilitates personal success (Sodhi, 2015). However, Goleman (1995) changed that when he indicated El and $\mathrm{SI}$ are better predictors in life compared to IQ. In terms of hierarchies of the human intelligence, El comes earlier than SI, however, early in adulthood the process can appear interchangeably (Wigglesworth, 2014). Mayer and Cobb (2000) also denote that spiritual intelligence can be effectively used as a foundation to optimize the emotional intelligence 
function. The finding of SI which denotes significant relationship on EI supported the argument that SI requires the ability to instill knowledge about how things effect each other which increases an individual's capacity to understand others at a higher level (Sodhi, 2016). This finding agrees with other studies that denotes high spiritual intelligence individuals translate better in the 'true cause' of behaviour without giving judgmental views and serve the 'true needs' by positing high emotional standards (Hosseini et al., 2010). A well balanced individual would have a high SI and El because they have the ability to combat stress and challenges in life. The stability in both will not only promote academic achievements but also develop positive health behaviours (Sodhi, 2016). High level of SI will also help students manage their laziness and avoid all other emotional disturbances which could lead to negative impacts on their level of achievement in the university. Therefore, $\mathrm{SI}$ is very much related with El.

Based on the findings for the fifth and sixth hypothesis, it can be concluded that SI and El has a significant relationship on SE since the null hypotheses were rejected. Like the previous studies (Madhumathi \& Suparna, 2017; Zhang et al., 2013; Gupta, 2012) SI has significant relationship on SE $(\beta=.300 ; C . R=4.136, p<.05)$. According to Charkhabi, Mortakavi, Alimohammadi \& Hayati (2014) developing spiritual values may promote wellness, enhancing the development of meaning and purpose in life. Research has demonstrated the benefits of spirituality among college students related to mental health, psychological well-being, health behaviour and coping skills. Spirituality thus, becomes an important aspect of a young adult such as college student healthy development. It addresses intrinsic aspects of life and directs individuals to understand authentic ways of living (Madhumathi \& Suparna, 2017).

Emotional intelligence is the ability to identify, understand, manage and utilize emotions to facilitate cognitive processing and relationships (Salovey \& Mayer, 1990). Bandura's (1977) social cognitive theory states that those with high self-efficacy believes that they are able to perform any given task successfully. In the present study, El was seen to significantly associate self-efficacy with $\beta=.235 ; C . R=3.256, p<.05$ : the way the students react emotionally attributes on the levels of one's self-efficacy. This result is coherent with other studies that states individuals with high trait of El are more flexible and can withstand pressure and stress and more likely to be more confident in life (Gupta, 2012). High level of emotional intelligence and self-efficacy would seem to be a natural phenomenon in reducing stress because by the sheer ability to identify, understand and utilization of cognitive processing would in itself improve stress management. At this point it dawned on the author a more meaningful study should be carried out in understanding qualitatively stress determinants among individuals in the present time.

Emotional intelligence (EI) does not mediate the relationship of spiritual intelligence (SI) on health behaviour (HB) (seventh hypothesis) but partially mediates spiritual intelligence and self-efficacy (SE) (eighth hypothesis). This finding is coherent with a study by Hanafi (2010) that dictates there is a stronger relationship between spiritual intelligence and performance indirectly rather than a direct one. So, the empirical result supports that there is a positive relationship between participants' spiritual intelligence and their performance through emotional intelligence as the mediator variable. This finding supports the Tischlers model where there is a relationship between spiritual intelligence, emotional intelligence and performance (Martin \& Hafer, 2009). 
Dulewicz and Higgs (2000) also found that capability based on emotional intelligence contributed about 36 percent factor to predict an organization's development, while intellectual intelligence only contributed about 27 percent, and the third factor which is called managerial quotient contributed about 16 percent. According to them, emotional intelligence gave the greatest effect among other intelligences which lead to the organization achievement. These findings also support perceived El, and suggest that El components contribute to an important element of wellbeing such as self-efficacy (Costa, Ripoll, Sanchez \& Carvalho, 2013).

The test on the role of self-efficacy (SE) as a mediator revealed that this construct acted as a partial mediator between spiritual intelligence (SI) and health behaviours (HB) (which was the ninth hypothesis). This finding is in congruence with several previous studies which relate to anxiety. For example, Jamshidi, Moghadam, Ghorbani and Farhoush (2018) and Noori (2016) found that students who have high spiritual intelligence have more faith in God's help will feel empowered and self-sufficient and automatically higher in self-efficacy. The role of self-efficacy would reduce test anxiety and consequently enhance in academic performance. There is limited studies that relate SE, SI and HB altogether. However, there are a few studies that investigate spiritual intelligence and self-efficacy on psychological well-being, mental health and health status (Adeyemo \& Adeleye, 2008); De Souza, Torres, Barbossa, De Lima \& De Souza, 2014) showed somewhat the relevant outcomes of the findings of self-efficacy associate with the health outcomes where according to De Souza et al. (2014) self-efficacy is positively related to promotive health behaviour.

\section{Conclusion}

Overall, this study has provided a better understanding concerning how spiritual intelligence (SI), emotional intelligence (EI), and self-efficacy (SE) affect health behaviours among undergraduates at Universiti Putra Malaysia using the suggested conceptual framework.

Among the six paths that were investigated in the proposed structural model, only five were seen to have significant relationship on the revised structural model. All predictors (SI, SE) have relationship on health behaviours except EI. Both SI and EI have relationship on SE. Furthermore, SI has a positive relationship on SE. This suggests that SI has a relationship or significant relationship on EI, SE and HB. Interestingly, SI was the main contributor to $\mathrm{HB}$. This finding is useful as the researcher has always thought that low SI as an important cause of immorality and de-civic values include health risk behaviours that has been portrayed by the current younger generation in Malaysia.

Two mediating variables of the proposed model were EI and SE. From the mediation results, EI was seen to mediate partially between SI and SE and SE were seen to mediate partially between $\mathrm{SI}$ and $\mathrm{HB}$. What this means is EI has some effects on the relationship between $\mathrm{SI}$ and $\mathrm{SE}$, and so as SE has some effects on the relationship between SI and SE. Indeed this result has paved the way to use a model based on the conceptual framework.

In this study, SI was seen as the main root or the distal predictors of HB while El as distalproximal and SE as the proximal predictor of HB. In the original TTI model, SI, and EI was arranged as distal predictors, however, the researcher has moved El as a distal-proximal predictor based 
on previous studies that denotes $\mathrm{SI}$ as the root of all intelligence which allows the intrapersonal and the interpersonal emotions to fill the gap between self and the other. However, El alone cannot help us bridge the gap. It needs SI to determine the path that is meaningful to us, and how meanings are placed in the world (Sodhi, 2016; Koohbanani, Dastjerdi, Vahidi, \& Ghani-Far, 2013; Goleman, 1995). Hopefully, the outcomes of the present study can fill the gap that exist in searching for models that could be used to identify the direct relationship of SI on HB as well as SE on HB. Hence, the conceptual framework can now be addressed as University Student Health Behaviour Model after confirming on the hypothesis based on the conceptual framework.

This study has provided some new thoughts and insights on measuring self-efficacy based on students' perceptions. Many researchers have identified SE as the most important predictor for health behaviour (Mathumardhi \& Suparna, 2016; Jamshidi et al., 2018), however, high SE will be meaningless if there is no authentic way in addressing intrinsic aspects of life in terms of spirituality (Mathumardi \& Suparna). SI and SE hand in hand help university students to become useful members of the society, as in case individuals who care about promotive health behaviours.

\section{Acknowledgements}

The authors are thankful to the Ministry of Higher Education Malaysia for the award of Fundamental Research Grant Scheme 05-01-16-1800FR (\#5524907).

\section{Corresponding Author}

Roxana Dev Omar Dev (PhD) is a senior lecturer at Faculty of Educational Studies, Universiti Putra Malaysia, 43400 Serdang, Selangor, Malaysia. Email: rdod@upm.edu.my

\section{References}

Abbey, A. (2002). Alcohol related sexual assault: A common problem among college students. Journal on Studies of Alcohol, 14, 118-128.

Adeyemo, D. A. \& Adeleye, A. T. (2008). Emotional intelligence, religiosity and self-efficacy as predictors of psychological well-being among secondary school adolescents in Ogbomoso, Nigeria. Europe's Journal of Psychology, 4(1), 2005-2012.

Ahghar, C. (2014). Effectiveness of the group's spiritual intelligence training on change of attitude towards drugs in students (Persian). Thought and Behaviour in Clinical Psychology, 8(30), 77-85.

Alaei, S., Zabihi, R., Ahmadi, A., Doosti, A. \& Saberi, S. M. (2017). Emotional intelligence, spiritual intelligence, self-esteem and self-control of substance abuse. International Neuropsychiatric Disease Journal, 9(4), 1-8.

Al-naggar, R. A., Bobryshev, Y. V., Aini, N., \& Mohd, B. (2013). Lifestyle practice among Malaysian university students. Asian Pacific Journal of Cancer Prevention, 14(3), 1895-1903.

Anye, E. T., Gallien, T. L., Bian, H., \& Moulton, M. (2013). The relationship between spiritual wellbeing and health-related quality of life in college students. Journal of American College 
Health, 61(7), 414-421.

Ardell, D. B. (1986). High level wellness: An alternative to doctors, drugs and disease. Berkley, CA: Ten Speed Press.

Azzam, H., \& Elghonemy, S. (2008). Emotional intelligence and substance abuse: A possible relation. Current Psychiatry, 15, 113-115.

Baron, R. M., \& Kenny, D. A. (1986). The moderator-mediator variable distinction in social psychological research: Conceptual, strategic, and statistical considerations. Journal of Personality and Social Psychology, 51, 1173-1182.

Bavarian, N., Flay, B. R., Ketcham, P. L., \& Smit, E. (2013). Development and psychometric properties of a theory-guided prescription stimulant misuse questionnaire for college students. Substance Use Misuse, 48(6), 457-469.

Bobroff, L. (2015). Healthstyle: A self-test. U.S. Department of Health and Human Services Public Health Service, DHHS Publication Number (PHS) 81-50155.

Breaux-Shropshire, T. L., Brown, K. C., Pryor, E. R., \& Maples, E. H. (2012). Relationship of blood pressure self-monitoring, medication adherence, self-efficacy, stage of change, and blood pressure control among municipal workers with hypertension. Workplace Health \& Safety, 60(7), 1-18.

Brechting, E. H., Brown, T. L., Salsman, J. M., Sayer, S. E., Holeman, V. T., \& Carlson, C. R. (2010). The role of religious beliefs and behaviours in predicting underage alcohol use. Journal of Child and Adolescent Substance, 19(4), $324-334$.

Burris, J. L., Smith, G. T., \& Carlson, C. R. (2009). Relations among religiousness, spirituality, and sexual practices. Journal of Sex Research, 46(4), 282-289.

Charkhabi, M., Mortazavi, A., Alimohammadi, S., \& Hayati, D. (2014). The effect of spiritual intelligence training on the indicators of mental health in Iranian students: An experimental study. Procedia-Social and Behavioural Sciences, 159, 355-358.

Claros, E., \& Sharma, M. (2012). The relationship between emotional intelligence and abuse of alcohol, marijuana, and tobacco among college students. Journal of Alcohol and Drug Education, 56, 8-37.

Costa, H., Ripoll, P., Sanhez, M., \& Carvalho, C. (2013). Emotional intelligence and self-efficacy: effects on psychological well-being in college students. The Spanish Journal of Psychology, 16, 50-57.

Darker, C., French, D., Eves, F., \& Sniehotta, F. (2010). An intervention to promote walking amongst the general population based on an 'extended 'theory of planned behaviour: A waiting list randomized controlled trial. Psychology and Health, 25(1), 71-88.

Dev, R. O. D., Fadilah, T. K., Soh, K. G., Chong, M. A., Fauzi, A. M. A., \& Ismi, A. I. (2018). Factors influencing health behaviours among Malaysian university students in a Malaysian public university. Malaysian Journal of Youth Studies, 18, 167-192.

Dev, R. O. D., Fadilah, T. K., Soh, K. G., Chong, M. A., Fauzi, A. M. A., \& Ismi, A. I. (2018). Emotional intelligence, spiritual intelligence, self-efficacy and health behaviours: Implications for quality health. International Journal of Academic Research in Business and Social Science, 8(7), 794-809. 
Dev, R. O. D., Fadilah, T. K., Soh, K. G., Fauzi, A. M. A., \& Ismi, A. I. (2018). Spiritual intelligence on health behaviours among Malaysian university students in a Malaysian public university: The mediating role of self-efficacy. Movement, Health \& Exercise Journal, $7(2)$, 53-64.

Dulewicz \& Higgs, M. (2000), Emotional intelligence: A review and evaluation study. Henley Management College, UK: Henley-on-Thames.

Ekpenyong, C. E., Daniel, N. E., \& Aribo, E. O. (2013). Associations between academic stressors, reaction to stress, coping strategies and musculoskeletal disorders among college students. European Journal of Health Sciences, 23(2), 98-112.

Fernández-Abascal, E. G., \& Martín-Díaz, M. D. (2015). Dimensions of emotional intelligence related to physical and mental health and to health behaviours. Frontiers in Psychology, 6 (317). doi: 10.3389/fpsyg. 2015.00317

Fernández-Berrocal, P., \& Cabello, R. (2016). Commentary: Dimensions of emotional intelligence related to physical and mental health and to health behaviours. Frontiers in Psychology, 7(441). doi:10.3389/fpsyg. 2016.00441

Flay, B. R., \& Petraitis, J. (1994). A new theory of health behaviour with implications for preventive interventions. Advances in Medical Sociology, 4, 19-44.

Flay, B. R., Snyder, F., \& Petraitis, J. (2009). The theory of triadic influence. Emerging Theories in Health Promotion Practice and Research, 2, 451-510.

Galanter, M., Dermatis, H., \& Santucci, C. (2012). Young people in alcoholics anonymous: The role of spiritual orientation and AA member affiliation. Journal of Addictive Diseases, $31(2), 173-182$

Ghee, A. C., \& Johnson, C. S. (2008). Emotional intelligence: a moderator of perceived alcohol peer norms and alcohol use. Journal of Drug Education, 38(1), 71-83.

Glanz, K., Rimer, B. K., \& Lewis, F. M. (2002). Health behaviour and education. Theory, research and practice. San Francisco, CA: Wiley \& Sons.

Goleman, D. (1995). Emotional intelligence: Why it can matter more than IQ. New York, NY: Bantham Press.

Gupta, G. (2012). Spiritual intelligence and emotional intelligence in relation to self-efficacy and self-regulation among college students. International Journal of Social Sciences \& Interdisciplinary Research, 1(2), 60-69.

Gwahula, R. (2018). Examining Key Macroeconomic Factors Influencing the Stock Market Performance: Evidence from Tanzania, International Journal of Academic Research in Accounting, Finance and Management Sciences 8 (2): 228-234.

Hair, J. J. F., Black, W. C., Babin, B. J. \& Anderson, R. E. (2010). Multivariate data analysis: A global perspective (7th ed.). Upper Saddle River, NJ: Pearson Education.

Hanafi, R. (2010). Spiritual intelligence, emotional intelligence and auditor's performance. Indonesian Journal of Accounting and Auditing, 14(1), 21-40.

Hassan, A. (2009). Emotional and spiritual intelligence as a basis for evaluating the national philosophy of education achievement. Research Journal of International Studies, 12, 5966. 
Hill, E. M., \& Maggi, S. (2011). Emotional intelligence and smoking: Protective and risk factors among Canadian young adults. Personality and Individual Differences, 51(1), 45-50.

Hosseini, M., Habibah E., Krauss, S. E., \& Aishah, S. (2010). A review study on spiritual intelligence, adolescence and spiritual intelligence, factors that may contribute to individual differences in spiritual intelligence and the related theories. Journal of Social Sciences, 6(3), 429-438.

Huntsinger, E. T., \& Luecken, L. J. (2004). Attachment relationship and health behaviour: The meditational role of self-esteem. Psychology and Health, 19(4), 515-526.

Hyde, J., Hankins, M., Deale, A., \& Marteau, T. M. (2008). Interventions to increase self-efficacy in the context of addiction behaviours: a systematic literature review. J Health of Psychol. 13(5), 607-23.

Jacobs, I., Wollny, A., Sim, C. W. \& Horsch, A. (2016). Mindfulness facets, trait emotional intelligence, emotional distress, and multiple health behaviours: A serial two-mediator model. Scandinavian Journal of Psychology, 57, 207-214.

Jamshidi, M. A., Moghadam, M. F., Ghorbani, S. \& Farhoush, M. (2018). Self-efficacy and resilience as mediators in the relationship between spiritual intelligence and test anxiety among high school students in Qom. Journal of Research on Religion and Health, 4(1), 721.

Kamran, A., Azadbakht, L., Sharifirad, G., Mahaki, B., \& Mohebi, S. (2015). The relationship between blood pressure and the structures of Pender's health promotion model in rural hypertensive patients. Journal of Education and Health Promotion, 4(29), 1-8.

Kimball, A. \& Freysinger, V. J. (2003). Leisure, stress and coping: The sport participation of collegiate student athletes. Leisure Sciences, 25, 115-141.

King, D. B. \& DeCicco, T. L. (2009). A viable model and self-report measure of spiritual intelligence. The International Journal of Transpersonal Studies, 28, 68-85.

King, D. B. (2008). Rethinking claims of spiritual intelligence: A definition, model, \& measure. Unpublished master's thesis, Trent University, Peterborough, Ontario, Canada.

Koohbanani, S. E., Dastjerdi, R., Vahidi, T., \& Ghani-Far, M. H. (2013). The relationship between spiritual intelligence and emotional intelligence with life satisfaction among Birjand gifted female high school students. Procedia of Social and Behavioural Sciences, 84, 314-320.

Kulis, S., Hodge, D. R., Ayers, S. L., Brown, E. F., \& Marsiglia, F. F. (2012). Spirituality and Religion: Intertwined Protective Factors for substance use among urban American Indian youth. The American Journal of Drug and Alcohol Abuse, 38(5), $444-449$.

Lana, A., Baizan, E. M., Faya-Ornia, G., \& Lopez, M. L. (2015). Emotional intelligence and health risk behaviours in nursing students. Journal of Nursing Education, 54(8), 464-467.

Madhumathi, C., \& Suparna, D. (2016). Spiritual intelligence among secondary school students with respect to gender and management. International Journal of Indian Psychology, 4(4), 78-84.

Martin, T. N. \& Hafer, J. C. (2009). Models of emotional intelligence, spiritual intelligence, and performance: A test of Tischler, Biberman, and McKeage. Journal of Management, Spirituality and Religion, 6(3), 247-257. 
Mathieu, J. E., \& Taylor, S. R. (2006). Clarifying conditions and decision points for mediational type inferences in Organizational Behavior. Journal of Organizational Behavior, 27(8), 1031-1056.

Mayer, J. D., \& Cobb, C. D. (2000). Educational policy on emotional intelligence: Does it make sense? Educational Psychology Review, 12, 163-183.

Mee, S. (2014). Self-efficacy: a mediator of smoking behaviour and depression among college students. Pediatric Nursing, 40(1), 9-15.

Noori, S. S. (2016). The relationship between spiritual intelligence and emotional intelligence and self-efficacy in students of Islamic Azad University of Dezful. Psychology and Religion, 9(1), 107-1022.

Pauline, J. S. (2013). Physical activity behaviours, motivation, and self-efficacy among college students. College Student Journal, 47(1), 1-7.

Peker, K., \& Bermek, G. (2011). Predictors of health-promoting behaviours among freshman dental students at Istanbul university. Journal of Dental Education, 75, 413-420.

Peraman, R., \& Parasuraman, S. (2016). Mobile phone mania: Arising global threat in public health. J Nat Sc Biol Med, 7, 198-200.

Piqueras, J. A., Kuhne, W., Vera-Villarroel, P., Straten, A. V. \& Cuijpers, P. (2011). Happiness and health behaviours in Chilean college students: A cross-sectional survey. BMC Public Health, 11(443), 1-10.

Quartiroli, A., \& Maeda, H. (2016). The effects of a lifetime physical fitness course on college students' health behaviours. International Journal of Exercise Science, 9(2), 136-148.

Rivers, S. E., Brackett, M. A., Omori, M., Sickler, C., Bertoli, M. C. \& Salovey, P. (2013). Emotion skills as a protective factor for risky behaviours among college students. Journal of College Student Development, 54(2), 172-183.

Saksvig, B. I., Gittelsohn, J., Harris, S. B., Hanley, A. J. G., Valente, T. W., \& Zinman, B. (2005). A pilot school-based healthy eating and physical activity intervention improves diet, food knowledge, and self-efficacy for native Canadian children. The Journal of Nutrition, 135(10), 2392-2398.

Salami, S. O. (2010). Emotional intelligence, self-efficacy, psychological wellbeing and students' attitudes: implications for quality education. European Journal of Educational Studies, 2(3), 247-257.

Sarafino, E. P. (2005). Health psychology: Biopsychosocial interactions (5th ed.). New York, NY: Wiley.

Schutte, N. S., Malouff, J. M., \& Bhullar, N. (2009). The Assessing Emotions Scale. In C. Stough, D. H. Saklofske, \& J. D. A. Parker (Eds.), Assessing emotional intelligence: Theory, research, and application (pp. 119-134). New York, NY: Springer.

Schutte, N. S., Malouff, J. M., Hall, L. E., Haggerty, D. J., Cooper, J. T., Golden, C. J., \& Dornheim, L. (1998). Development and validation of measure of emotional intelligence. Personality and Individual Differences, 25, 167-177.

Schutte, N. S., Malouff, J. M., Thorsteinsson, E. B., Bhullar, N., \& Rooke, S. E. (2007). A metaanalytic investigation of the relationship between emotional intelligence and health. 
Personality and Individual Differences, 25, 167-177.

Schwarzer, R., \& Jerusalem, M. (1995). Generalized Self-Efficacy scale. In J. Weinman, S. Wright, \& M. Johnston (Eds), Measures in health psychology: A user's portfolio. Causal and control beliefs (pp. 35-37). Windsor, UK: Nfer-Nelson.

Schwarzer, R., \& Warner, L. M. (2013). Perceived self-efficacy and its relationship to resilience. In S. Prince-Embury \& D. H. Saklofske (Eds.), The Springer series on human exceptionality: Resilience in children, adolescents, and adults: Translating research into practice (pp. 139150). doi: 10.1007/978-1-4614-4939-3_10

Serrat, O. (2017). Understanding and developing emotional intelligence. Knowledge Solutions, 329-339.

So, E. S. \& Park, B. M. (2016). Health behaviours and academic performance among Korean adolescents. Asian Nursing Research, 10, 123-127.

Sodhi, R. (2016). Emotional intelligence and spirituality: A review. The International Journal of Indian Psychology, 4(1), 71-86.

Souza, D. L. A. S., Torres, A. R. R., Barbosa, G. A., Lima, D. T. J. S., \& Souza, D. L. E. C. (2014). Selfefficacy as a mediator of the relationship between subjective well-being and general health of military cadets. Cad. Saude Publica, 30(11), 2309-2319.

Tehrani, F. J., \& Nikpour, S. (2014). Effect of health on knowledge, self-efficacy and health behaviours of women with urinary tract infection. International Journal of Urological Nursing, 8(1), 3-14.

Ultimate Intelligence. New York, NY: Bloomsbury.

Valois, R. F., Zullig, K. J., \& Hunter, A. A. (2013). Association between adolescent suicide ideation, suicide attempts, and emotional self-efficacy. Journal of Child and Family Studies, 24, 112.

Veselska, Z., Madarasova, G. A., Reijneveld, S. A., \& Dijk, V. J. P. (2011). Socio-economic status and physical activity among adolescents: the mediating role of self-efficacy. Public Health, 125(11), 763-768.

Wigglesworth, C. (2014). Deep intelligence: The critical intelligences for leadership success in the 21st century. Deep Change, 1-8.

Wills, T.A, Year, M.A, \& Sandy, J. (2003). Buffering effects of religiosity for adolescent substance use. Psychology of Addictive Behaviours, 17(1), 24-31.

World Health Organization. (2014). World health statistics. Geneva, Switzerland: WHO Press.

Zhang, K. C., Hui, C. H., Lam, J., Lau, E. Y. Y., Cheung, S. F., \& Mok, D. S. Y. (2014). Personal spiritual values and quality of life: Evidence from Chinese college students. Journal of Religion and Health, 53(4), 986-1002.

Zohar, D. \& Marshall, I. (2000). Spiritual Intelligence: The 